\title{
Zinc and childhood infectious disease morbidity and mortality
}

\author{
Robert E. Black* and Sunil Sazawal \\ Department of International Health, School of Public Health, Johns Hopkins University 615 N. Wolfe Street, \\ Baltimore, MD 21205, USA
}

\begin{abstract}
Zinc is an essential mineral and deficiency results in abnormal immune function and higher rates of infectious diseases. Randomized controlled trials of zinc supplementation have been conducted in children in developing countries to determine effects on infectious disease morbidity and mortality. Zinc-supplemented children have been found to have lower rates of diarrhea, pneumonia and malaria in comparison with children not given zinc. Zinc used as an adjunct to fluid and dietary management of acute and persistent diarrhea has been found to reduce diarrheal duration and severity. Preliminary evidence suggests that zinc supplementation in children in poor developing country settings may also reduce infant mortality, but larger trials are needed to address this important issue. Preventive and therapeutic interventions should be implemented in developing countries where zinc deficiency is likely to be prevalent.
\end{abstract}

Diarrhea: Malaria: Malnutrition: Pneumonia: Zinc

\section{Introduction}

Zinc is an essential mineral, critical to human metabolism, growth and immune function (Aggett \& Comerford, 1995). With zinc deficiency epithelial barriers are compromised and many components of the immune system malfunction (Shankar \& Prasad, 1998). This decrease in immunological competence may lead to a higher risk of infectious diseases or a greater severity of illnesses. Such an association of zinc deficiency with infectious disease morbidity, observed in clinical and field studies (Prasad, 1985; Bahl et al. 1998), has been shown to be a causal relationship through randomized controlled trials of zinc in prevention of disease. Trials of zinc in the treatment of diarrhea provide evidence of benefit on episode outcomes, as well. The benefits demonstrated in these trials, along with biological measures, such as plasma or tissue zinc, or dietary intake assessments, suggest that zinc deficiency is prevalent in children in developing countries and has important effects on morbidity and possibly mortality.

For this review, all published and unpublished randomized controlled trials of oral zinc supplementation in preschool children in developing countries were sought by systematic researching of bibliographic databases, by references from publications and by contacts with funding agencies and experts in the field. Special efforts were made to identify unpublished reports to avoid the possible bias of using published reports, which are possibly more likely to have positive findings. The selection criteria for the review included double-blind trials containing at least one half of the United States Recommended Daily Allowance of zinc $(5 \mathrm{mg} / \mathrm{d}$ in infants and $10 \mathrm{mg} / \mathrm{d}$ in children $1-4$ years old).
The prevention trials included in this review were those that provided the oral zinc supplements and conducted concurrent household-level morbidity assessments for at least 4 weeks. The therapeutic trials included in this review were those that gave the supplement as an adjunct to fluid and dietary therapy in acute $(<14 \mathrm{~d}$ pre-enrolment duration) or persistent ( $\geq 14 \mathrm{~d}$ pre-enrolment duration) diarrhea. From the search twenty-six trials were identified, eight were prevention trials, and five each were therapeutic trials in acute and persistent diarrhea.

The included studies are reviewed providing the effect size and statistical significance from the original publication or in some cases from a pooled analysis. The pooled analysis was performed with seven of the eight prevention trials, three of five acute diarrhea treatment trials and four of five persistent diarrhea treatment trials. The other four trials either did not have original data available for analysis (two) or were not provided by the investigators (two).

The pooled analysis of prevention trials was performed with the Confidence Profile Method (Eddy et al. 1992a) using FAST*PRO Software, Version 1.8 (Eddy et al. 1992b). A joint posterior probability distribution was estimated with a random effects hierarchical model (Bryk et al. 1989) and Odds Ratio with $95 \%$ Confidence Intervals calculated for each and overall study. For the pooled analysis of therapeutic trials on duration of diarrhea Cox survival regression models were used, stratified by individual trial, with continuation of the episode after enrolment modeled as the dependent variable and treatment groups and pre-enrolment duration as independent variables. These models permitted calculation of the Relative Hazard for continuation of the episode (time until diarrhea

*Corresponding author: Dr Robert E. Black, fax +410955 7159, email rblack@jhsph.edu 


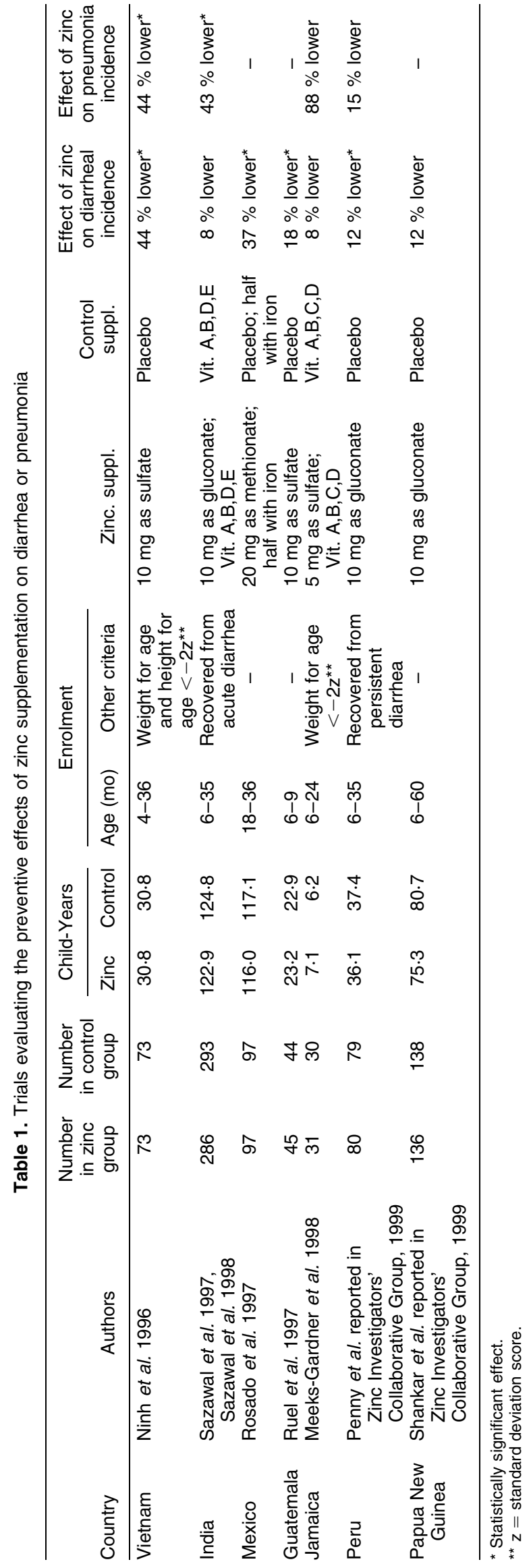

ceased) with its $95 \%$ Confidence Interval (Cox \& Oakes, 1984; Allison 1995; Delong et al. 1994). The control group was coded as 1 and zinc group as 0 , and a Relative Hazard of $<1$ was a beneficial effect consistent with the beneficial effect expressed by the Odds Ratio. The dependent outcomes of treatment failure or death in persistent diarrhea were analyzed using logistic regression models stratified by trial, with treatment group, subgroup categories and potential interaction terms as independent variables to calculate the Odds Ratio and $95 \%$ Confidence Intervals (Matthews \& Farewell, 1988).

\section{Zinc supplementation effects on prevention of infectious diseases}

Zinc deficiency has been associated with higher rates of infectious diseases, including skin infections, diarrhea, respiratory infections, and malaria, as well as with delayed wound healing (Prasad, 1985; Bahl et al. 1998; Black, 1998). With regard to outcomes in children in developing countries, the best studied have been diarrhea and lower respiratory tract infections, although limited information on malaria is also available. Due to the difficulty in assessing zinc status of children in a population, most of the information on the role of zinc deficiency in the risk of infectious disease is available from randomized controlled trials of zinc supplementation. In these trials when zinc is the only experimental variable, there is direct causal evidence that additional zinc can result in a lower rate of infectious diseases.

Seven trials of zinc supplementation provide information on outcomes of diarrhea and four of these include information on pneumonia (Table 1). These trials were done in preschool children who were representative of poor developing country populations, and in two of the studies more poorly nourished children were selected for enrolment into the trial. These trials were done in seven different countries representing a wide range of development and nutritional status of the population. The results with regard to diarrheal incidence are consistent in showing that zincsupplemented children have lower rates of diarrhea than those of the control children. Individually, in most of these studies statistically significant differences were found in diarrheal incidence and a pooled analysis showed that the overall incidence of diarrhea in zinc-supplemented children was $18 \%(95 \%$ CI $7 \%, 28 \%)$ less than in unsupplemented children (Zinc Investigators' Collaborative Group, 1999). Since it also appears that zinc supplements reduce the duration of diarrhea (Sazawal et al. 1995), it is not surprising that the overall effect in the pooled analysis on the prevalence of diarrhea was greater than the effect on incidence, i.e. $25 \%(95 \%$ CI $12 \%, 37 \%)$ lower prevalence of diarrhea in the zinc-supplemented children (Zinc Investigators' Collaborative Group, 1999). While children in these trials who were in their second or later year of life ( $v$. infants), had lower plasma zinc concentrations, were wasted or were female had a tendency to have greater effects of zinc supplementation, the comparison of effects between these subgroups of children did not show statistically significant differences (Zinc Investigators' Collaborative Group, 1999). 
Fewer studies provide information on the effects of zinc supplementation on the incidence of pneumonia and the original data from these trials have been examined in the pooled analysis (Zinc Investigators' Collaborative Group, 1999) (Table 1). The four studies available consistently show that zinc-supplemented children have lower rates of pneumonia and two of these studies showed sizeable and statistically significant effects individually. The other two studies had smaller numbers of subjects and the differences did not reach statistical significance. In an overall pooled analysis, there was a $41 \%(95 \%$ CI $17 \%, 59 \%)$ lower rate of pneumonia in zinc-supplemented children (Zinc Investigators' Collaborative Group, 1999).

Only two randomized controlled trials provide information on the effects of zinc supplementation on clinical attacks of malaria. In Gambian children with a twiceweekly $70 \mathrm{mg}$ zinc supplement, there was $30 \%$ reduction in clinic visits due to malaria, which was of only borderline statistical significance in this small study (Bates et al. 1993). In a larger trial with daily zinc supplementation using $10 \mathrm{mg}$ of zinc gluconate in Papua New Guinea, there was a significant reduction of $40 \%$ in clinic-based Plasmodium falciparum malaria rates and a higher efficacy (70 \%) for clinical attacks with parasite densities of more than 100 000:1 (Shankar et al. in press).

\section{Therapeutic effects of zinc during diarrhea}

The therapeutic effects of zinc supplements during diarrhea have been investigated in five trials in acute diarrhea and five additional trials in persistent diarrhea. These studies reveal consistent benefits of zinc supplementation. In the acute diarrhea studies (Table 2) zinc supplementation generally resulted in shorter diarrheal episodes and a reduced likelihood that the episode would continue for more than 7 days after enrolment in the study. Not all of the apparent effects were statistically significant, but some of the small studies had low statistical power. A pooled analysis of zinc supplementation in acute diarrhea trials for which original data could be obtained (Sazawal et al. 1995; Roy et al. 1997; Hidayat et al. 1998) revealed an overall $15 \%$ (95 \% CI $5 \%, 24 \%$ ) lower probability of continuing diarrhea in the supplemented group (Zinc Investigators' Collaborative Group, 2000). Several studies also reported reductions in episode severity, as measured by frequency of watery stools or measured stool output. (Sachdev et al. 1988; Sazawal et al. 1995; Roy et al. 1997)

The five trials addressing the effect of zinc supplementation in persistent diarrhea likewise showed benefits with zinc supplementation (Table 3). Generally, the studies revealed that supplementation was associated with a shorter episode duration and the pooled analysis with four trials (Roy et al. 1998; Penny et al. 1999; Bhutta et al. 1999; Khatun 1998) indicated that children in these trials had $24 \%(95 \%$ CI $9 \%, 37 \%)$ lower probability of continuing diarrhea, if they received the zinc supplement (Zinc Investigators' Collaborative Group, 2000). There was also a suggestion of reduced episode severity in one trial (Sachdev et al. 1990), but not in the second (Bhutta et al. 1999). Importantly in some trials, large reductions in the rate of treatment failure or death were reported. Overall in 


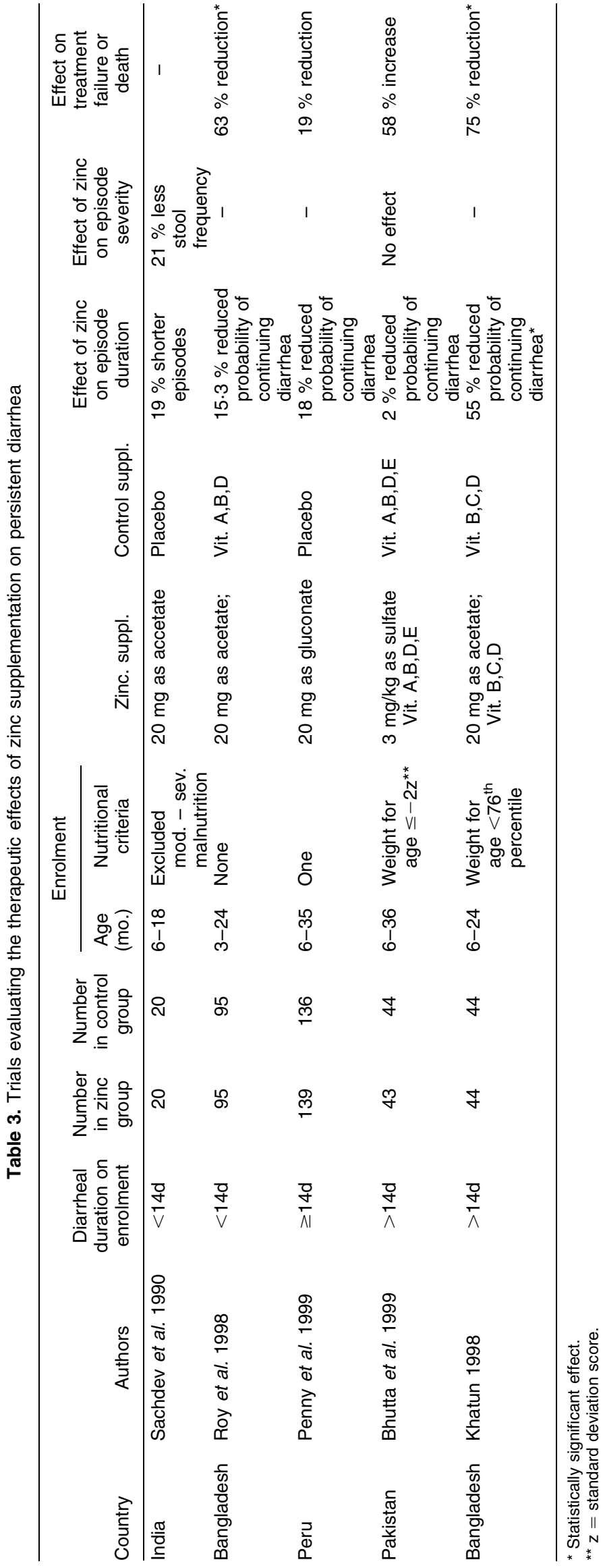

the pooled analysis, there was a $42 \%(95 \%$ CI $10 \%$, $63 \%)$ reduced rate of treatment failure or death in children given zinc supplements. For this outcome the trials were significantly heterogeneous $(P=0 \cdot 04)$, which was mainly due to the results in the study in Pakistan.

\section{Effect of zinc supplementation on child mortality}

Pneumonia and diarrhea are the two most common causes of death in children in developing countries and malaria also contributes substantially in many settings. With the large and consistent effects of zinc supplementation on the incidence and in some cases severity of these infectious diseases, one might hypothesize an effect on child mortality. None of the studies of zinc supplementation conducted to date have been of substantial size to fully address the effects on mortality. One study recently completed in India does provide preliminary evidence that zinc-supplemented infants have a lower rate of overall mortality (Sazawal et al. 1999). In this trial among 1250 small for gestational age infants, studied from 1 to 9 months of age there was $67 \%$ reduction in mortality in zinc-supplemented infants. Supplementation with selected other vitamins and minerals, including iron, was not associated with a significant reduction in mortality in this four-cell factorial design trial.

\section{Conclusions}

There is now evidence that zinc supplementation can prevent episodes of diarrhea and pneumonia, as well as possibly malaria, and can improve the outcome of acute and persistent diarrhea. It will be important to confirm these findings, especially those for pneumonia and malaria, for which results from diverse settings are limited. Additionally, it will be important to evaluate the effects of zinc supplementation on child mortality in potentially vulnerable developing country populations. Plans are underway to conduct such trials in at least three settings, i.e. India, Nepal and Zanzibar; these studies should start within the next year. However it appears that there is ample evidence to move forward to explore public health applications, using zinc either preventively in children or therapeutically for diarrhea. For the preventive uses of zinc, there is a need to evaluate various ways to improve the zinc nutriture of children in developing countries. These include improving the dietary sources and availability of zinc, fortifying foods with zinc, and supplementation programs. Therapeutic uses of zinc in diarrhea should be studied in regard to feasible modes of delivery. For both preventive and therapeutic applications the cost-effectiveness should be assessed and compared with alternative interventions.

\section{References}

Aggett PJ \& Comerford JG (1995) Zinc and human health. Nutrition Reviews 53, S16-S22.

Allison PD (1995) Survival Analysis Using the SAS System. A Practical Guide, pp. 233-249. Cary, NC: SAS Institute Inc.

Bahl R, Bhandari N, Hambidge KM \& Bhan MK (1998) Plasma zinc as a predictor of diarrhea and respiratory morbidity in 
children in an urban slum setting. American Journal of Clinical Nutrition 68, 414S-417S.

Bates CJ, Evans PH, Dardeene M, Prentice A, Lunn PG, Northrop-Clewes CA, Hoare S, Cole TJ, Horan SJ, Longman SC, Stirling D \& Aggett PJ (1993) A trial of zinc supplementation in young rural Gambian children. British Journal of Nutrition 69, 243-255.

Bhutta ZA, Nizami SQ \& Isani Z (1999) Zinc supplementation in malnourished children with persistent diarrhea in Pakistan. Pediatrics 103, 1-9.

Black RE (1998) Therapeutic and preventive effects of zinc on serious childhood infectious diseases in developing countries. American Journal of Clinical Nutrition 68S, 476S-479S.

Bryk AS, Raudenbrush SW, Seltzer M \& Congdon R (1989) Introduction to HLM: Computer Program and User's Guide. 2nd edition. Chicago, IL: University of Chicago, Department of Education.

Cox DR \& Oakes D (1984) Analysis of Survival Data. London: Chapman \& Hall.

Delong DM, Guirguis GH \& So YC (1994) Efficient calculations for subset selection probabilities with application to Cox regression. Biometrika 81, 607-611.

Eddy DM, Hasselblad V \& Shachter R (1992) In Meta-analysis by the Confidence Profile Method. San Diego, CA: Academic Press, Inc.

Eddy DM, Hasselblad V \& Shachter R (1992) FAST*Pro: Software for Meta-analysis by the Confidence Profile Method. San Diego, CA: Academic Press, Inc.

Faruque ASG, Mahalanabis D, Haque SS, Fuchs GJ \& Habte D (1999) Double-blind, randomized, controlled trial of zinc or vitamin A supplementation in children with acute diarrhoea. Acta Paediatrica 88, 154-160.

Hidayat A, Achadi A, Sunoto \& Soedarmo AP (1998) The effect of zinc supplementation in children under three years of age with acute diarrhea in Indonesia. Medical Journal of Indonesia 7, 237-241.

Khatun UHS (1998) Impact of zinc and vitamin A supplementation in malnourished hospitalized children suffering from persistent diarrhoea. Thesis submitted to the University of Dhaka for the degree of Doctor of Philosophy in the Institute of Nutrition \& Food Science.

Matthews DE \& Farewell VT (1988) Using and Understanding Medical Statistics 2nd edition. pp. 164-166. Basel, Switzerland: Karger.

Meeks-Gardner JM, Witter MM \& Ramdath DD (1998) Zinc supplementation effects on the growth and morbidity of undernourished Jamaican children. European Journal of Clinical Nutrition 52, 34-39.

Ninh X, Thissen P, Colletee L, Gerard G, Khoi H \& Ketelslegers M (1996) Zinc supplementation increases growth and circulating insulin-like growth factor I (IGF-I) in growth retarded Vietnamese children. American Journal of Clinical Nutrition 63, 514-519.

Penny E, Peerson M, Marin M, Duran A, Lanata F, Lonnerdal B, Black R \& Brown K (1999) Randomized community-based trial of the effect of zinc supplementation, with and without other micronutrients, on the duration of persistent childhood diarrhea in Lima, Peru. Journal of Pediatrics 135, 208-217.

Prasad AS (1985) Clinical manifestations of zinc deficiency. Annual Review of Nutrition 5, 341-363.
Rosado JL, Lopez P, Munoz E, Martinez H \& Allen H (1997) Zinc supplementation reduced morbidity, but neither zinc nor iron supplementation affected growth or body composition of Mexican preschoolers. American Journal of Clinical Nutrition 65, 13-19.

Roy SK, Tomkins AM, Akramuzzaman SM, Behrens RH, Haider R, Mahalanabis D \& Fuchs G (1997) Randomized controlled trial of zinc supplementation in malnourished Bangladeshi children with acute diarrhoea. Archives of Disease in Childhood 77, 196-200.

Roy SK, Tomkins AM, Mahalanabis D, Akramuzzaman SM, Haider R, Behrens RH \& Fuchs G (1998) Impact of zinc supplementation on persistent diarrhoea in malnourished Bangladeshi children. Acta Paediatrica 87, 1235-1239.

Ruel MT, Rivera JA, Santizo MC, Lonnerdal B \& Brown KH (1997) The impact of zinc supplementation on morbidity from diarrhea and respiratory infections among young rural Guatemalan children. Pediatrics 99, 808-813.

Sachdev HPS, Mittal NK, Mittal SK \& Yadav HS (1988) A controlled trial on utility of oral zinc supplementation in acute dehydrating diarrhea in infants. Journal of Pediatric Gastroenterology 7, 877-881.

Sachdev HPS, Mittal NK \& Yadav HS (1990) Oral zinc supplementation in persistent diarrhea in infants. Annals of Tropical Paediatrics 10, 63-69.

Sazawal S, Black R, Bhan M, Bhandari N, Sinha A \& Jalla S (1995) Zinc supplementation in young children with acute diarrhea in India. New England Journal of Medicine 333, 839-844.

Sazawal S, Black RE, Bhan MK, Jalla S, Sinha A \& Bhandari N (1997) Efficacy of zinc supplementation in reducing the incidence and prevalence of acute diarrhea-a communitybased, double-blind, controller trial. American Journal of Clinical Nutrition 66, 413-418.

Sazawal S, Black RE, Jalla A, Mazumdar S, Sinha A \& Bhan MK (1998) Zinc supplementation reduces the incidence of acute lower respiratory infections in infants and preschool children: a double-blind, controlled trial. Pediatrics 102, 1-5.

Sazawal S, Black RE, Menon VP, Dhingra U, Dhingra P, Mazumder S, Caulfield L \& Khosla S (1999) Effects of zinc and mineral supplementation in small for gestational age infants on growth and mortality. FASEB Journal A376,

Shankar AH, Genton B, Baisor M, Paino J, Tamja S, Adiguma T, Wu L, Rare L, Bannon D, Tielsch JM, West KP \& Alpens MP (2000) The influence of zinc supplementation on morbidity due to Plasmodium faliciparum: a randomized trial in preschool children in Papua New Guinea. American Journal of Tropical Medicine 62, 663-669.

Shankar AH \& Prasad AS (1998) Zinc and immune function: The biological basis of altered resistance to infection. American Journal of Clinical Nutrition 68, 437S-463S.

Zinc Investigators' Collaborative Group (1999) Prevention of diarrhea and pneumonia by zinc supplementation in children in developing countries: pooled analysis of randomized controlled trials. Journal of Pediatrics 135, 689-697.

Zinc Investigators' Collaborative Group (2000) Therapeutic effects of zinc in acute and persistent diarrhea in children in developing countries: pooled analysis of randomized controlled trials. American Journal of Clinical Nutrition 72, 1516-1522. 